\title{
Synthesis and magnetic properties of $\mathrm{Mn}_{1-x} \mathrm{Co}_{x} \mathrm{Fe}_{2} \mathrm{O}_{4}$ nanoparticles Qingwei Qiu ${ }^{a}$, Xiaowen Xu \\ School of information and electronics, Beijing Institute of Technology, Beijing, 100081, China \\ aemail: qiuqingwei@bit.edu.cn, bemail: mw219@bit.edu.cn
}

Keywords: Ferrite nanoparticles; Magnetic properties; Thermal decomposition method

\begin{abstract}
Chemically mixed $\mathrm{Mn}_{1-\mathrm{x}} \mathrm{Co}_{\mathrm{x}} \mathrm{Fe}_{2} \mathrm{O}_{4}$ nanoparticles with the size about $8 \mathrm{~nm}$ were synthesized by thermal decomposition method. The content of Co element $\mathrm{x}$ varied from 0.02 to 0.08. Magnetic measurement indicated that $8 \mathrm{~nm} \mathrm{Mn}_{1-\mathrm{x}} \mathrm{Co}_{\mathrm{x}} \mathrm{Fe}_{2} \mathrm{O}_{4}$ nanoparticles were superparamagnetic at room temperature and ferromagnetic at the temperature of $5 \mathrm{~K}$. Both the blocking temperature and coercivity of $\mathrm{Mn}_{1-x} \mathrm{Co}_{x} \mathrm{Fe}_{2} \mathrm{O}_{4}$ nanoparticles increased with increasing Co addition. $\mathrm{Mn}_{1-\mathrm{x}} \mathrm{Co}_{\mathrm{x}} \mathrm{Fe}_{2} \mathrm{O}_{4}$ nanoparticles showed not only high saturated magnetization but also large coercivity at low temperature, which have great potential in magnetic nanodevice and biomagnetic applications.
\end{abstract}

\section{Introduction}

Magnetic iron oxide nanoparticles have been widely investigated for their novel properties as well as their numerous applications in technological field and biomedicine[1-5]. The cubic spinel $\mathrm{MFe}_{2} \mathrm{O}_{4}$ has a cubic inverse spinel structure with oxygen forming a fcc closed packing, whereM ${ }^{2+}$ and $\mathrm{Fe}^{3+}$ occupy either tetrahedral or octahedral sites. By adjusting the chemical identity of $\mathrm{M}$, the $\mathrm{MFe}_{2} \mathrm{O}_{4}$ nanoparticles can be engineered to provide a wide range of magnetic properties. It is well known that cobalt ferrite $\left(\mathrm{CoFe}_{2} \mathrm{O}_{4}\right)$ is a hard magnetic material with large magnetocrystalline anisotropy, having been considered as an excellent candidate for magnetic recording media[6,7]. On the other hand, manganese ferrite $\left(\mathrm{MnFe}_{2} \mathrm{O}_{4}\right)$ is a typical soft ferrite with much smaller magnetocrystalline anisotropy, which is suitable for biomedical applications[8]. Bimagnetic nanoparticles $\mathrm{MnFe}_{2} \mathrm{O}_{4} @ \mathrm{CoFe}_{2} \mathrm{O}_{4}$ in a core-shell architecture have been extensively studied[9,10]. The exchange coupling between the core and shell can be tuned by adjusting the thickness of shell and the size of core. Exchange coupled nanoparticles show very unique magnetic properties, attracting extensive scientific and technological interest[11].However, precise control of exchange coupling between the core and shell is inconvenient to achieve because it call for the core and shell with extremely narrow size distribution and at least two-step synthesis. By contrast, magnetocrystalline anisotropy is easy to tuned by mixing Co and Mn into ferrite. Most excitingly, this was obtained by a one-pot reaction without multiple coatings, with all magnetic properties controlled conveniently by doping. In this paper, magnetocrystalline anisotropy can be tuned through composition control of a quaternary $\left(\mathrm{Co}_{x} \mathrm{Mn}_{1-\mathrm{x}}\right) \mathrm{Fe}_{2} \mathrm{O}_{4}$ mixed ferrite nanoparticles. By varying $\mathrm{Mn}$ :Co ratio, blocking temperature, coercivity, and other magnetic properties can be systematically changed.

\section{Experiments}

$\mathrm{Fe}(\mathrm{acac})_{3}$ (2mmol), $\mathrm{Mn}(\mathrm{acac})_{2}$ and $\mathrm{Co}(\mathrm{acac})_{2}$ (total $\left.1 \mathrm{mmol}\right)$, 1,2-hexadecanediol(10 mmol)oleic acid(3 mmol), oleylamine ( $3 \mathrm{mmol})$, and $20 \mathrm{~mL}$ benzyl ether was mixed and magnetically stirred under a flow of nitrogen. The mixture was first heated at120C for 30 minutes to remove the low boiling solvent, then to $200 \mathrm{C}$ for 1 hour. At a ramping rate of $10 \mathrm{C} \mathrm{min}^{-1}$ the solution was further heated to reflux ( 300C) and kept at 300C for 1 hour. The solution was cooled down to room temperature by removing the heat source. The mixtures were precipitated with ethanol, centrifuged to remove the solvent, and dispersed in hexane.

The nanoparticle size and morphology were characterized by transmission electron microscopy 
(TEM) using a JEOL model 4000EX microscope. The magnetic hysteresis loops were measured using a Quantum Design Physical Property Measurement System (PPMS) model 6000.

\section{Results and discussion}

The composition of $\mathrm{Mn}_{1-\mathrm{x}} \mathrm{Co}_{\mathrm{x}} \mathrm{Fe}_{2} \mathrm{O}_{4}$ nanoparticles was conveniently tuned by changing the ratio of $\mathrm{Mn}(\mathrm{acac})_{2}$ : $\mathrm{Co}(\mathrm{acac})_{2}$. The morphology of the as-synthesized $\mathrm{Mn}_{1-\mathrm{x}} \mathrm{Co}_{\mathrm{x}} \mathrm{Fe}_{2} \mathrm{O}_{4}$ nanoparticles was characterized by TEM, as shown in figure1. These nanoparticles have an average size of $8 \mathrm{~nm}$ with a spherical shape.

(a)

(b)

(c)

Figure 1 TEM images of $\mathrm{Mn}_{1-\mathrm{x}} \mathrm{Co}_{\mathrm{x}} \mathrm{Fe}_{2} \mathrm{O}_{4}$ nanoparticles (a) $\mathrm{x}=0.02$ (b) $\mathrm{x}=0.06$ (c) $\mathrm{x}=0.08$

Magnetic properties of $\mathrm{Mn}_{1-\mathrm{x}} \mathrm{Co}_{\mathrm{x}} \mathrm{Fe}_{2} \mathrm{O}_{4}$ nanoparticles at both room temperature and $5 \mathrm{~K}$ were measured by PPMS. Figure 2 shows the hysteresis loops of $\mathrm{Mn}_{1-\mathrm{x}} \mathrm{Co}_{\mathrm{x}} \mathrm{Fe}_{2} \mathrm{O}_{4}$ nanoparticles. All three samples show superparamagnetic at room temperature and ferromagnetic at $5 \mathrm{~K}$. The coercivity of nanoparticles at low temperature increases with increasing Co addition. As the Co amount varied from 0.02 to 0.08 , the coercivity at $5 \mathrm{~K}$ increased from about 600 Oe to 2500 Oe. Incorporation of Co cation in the Fe-O matrix can greatly increases the magnetic anisotropy of the materials leading to enhancement of coercivity. On the other hand, the saturated magnetization of $\mathrm{Mn}_{1-\mathrm{x}} \mathrm{Co}_{\mathrm{x}} \mathrm{Fe}_{2} \mathrm{O}_{4}$ nanoparticles decreases slightly with increasing Co content. It is well known that manganese ferrite shows higher saturated magnetization than that of cobalt ferrite. Doping Co in manganese ferrite can resulting the reduce of saturated magnetization.
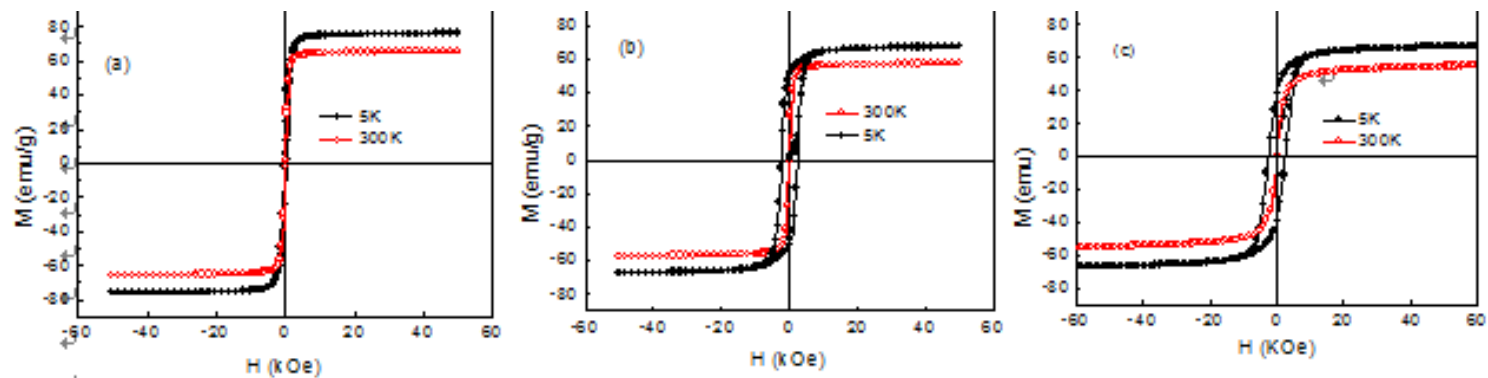

Figure 2 Hysteresis loops of $\mathrm{Mn}_{1-\mathrm{x}} \mathrm{Co}_{\mathrm{x}} \mathrm{Fe}_{2} \mathrm{O}_{4}$ nanoparticles (a) $\mathrm{x}=0.02$ (b) $\mathrm{x}=0.06$ (c) $\mathrm{x}=0.08$

With decreasing particle size, the magnetic stability of nanoparticles will become an important issue in technological applications due to thermal agitation. Each nanoparticle becomes a single magnetic domain and shows superparamagnetic behavior when the temperature is above the blocking temperature $T_{B}$. The blocking temperature $T_{B}$ of superparamagnetic nanoparticles can be obtained from low-field zero-field cooled (ZFC) and field-cooled (FC) curve, which is defined as

$$
\mathrm{T}_{\mathrm{B}}=\mathrm{U} /\left[\mathrm{k}_{\mathrm{B}} \ln \left(\mathrm{t}_{\mathrm{m}} / \tau_{0}\right)\right]
$$

where $U$ is the anisotropy energy, $\tau_{0}$ is the attempt frequency of the order of $10^{-9}-10^{-12} \mathrm{~s}, \mathrm{k}_{\mathrm{B}}$ is the 
Boltzmann constant, $t_{m}$ is the measuring time. If the temperature is above $T_{B}$, nanoparticles behave superparamagnetically; nanoparticles behave ferromagnetic when the temperature is below $T_{B}$. Figure 3 is ZFC and FC curves of $\mathrm{Mn}_{1-\mathrm{x}} \mathrm{Co}_{\mathrm{x}} \mathrm{Fe}_{2} \mathrm{O}_{4}$ nanoparticles, where FC curves was measured at 100Oe field.ZFC curves of all nanoparticles appear a peak corresponding to the blocking temperature $\mathrm{T}_{\mathrm{B}}$. The peak in a low-field ZFC curve is the consequence of the competition between the decrease in the moments of the superparamagnetic particles and the increase in the moments of the newly relaxed larger particles. $\mathrm{T}_{\mathrm{B}}$ estimated from $\mathrm{ZFC}$ curves for $\mathrm{x}=0.02,0.06$, and 0.08 is about $80 \mathrm{~K}, 140 \mathrm{~K}$, and $170 \mathrm{~K}$ respectively.
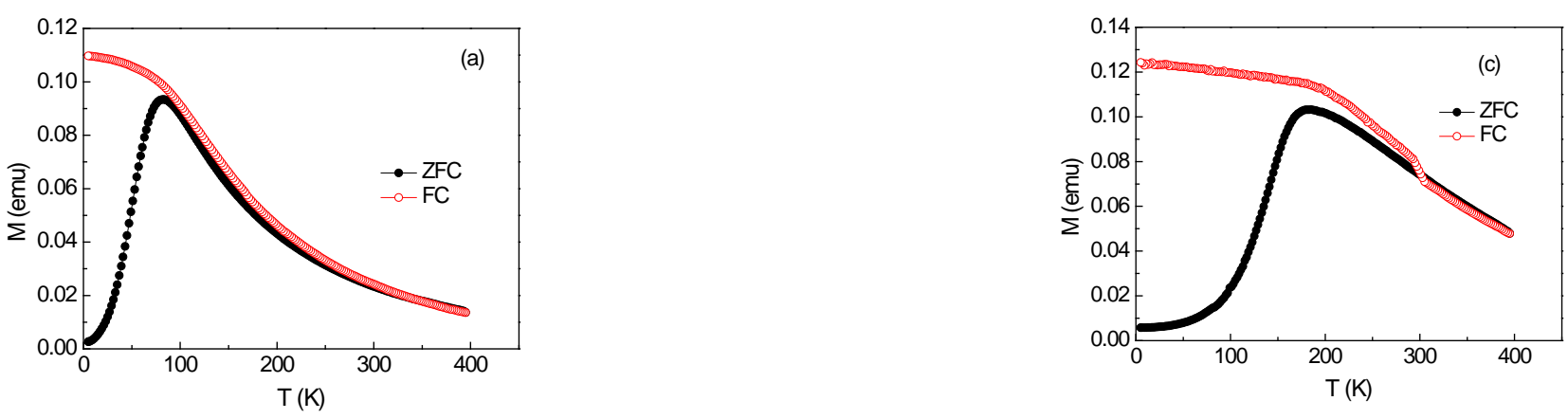

Figure 3 ZFC and FC curves of $\mathrm{Mn}_{1-\mathrm{x}} \mathrm{Co}_{\mathrm{x}} \mathrm{Fe}_{2} \mathrm{O}_{4}$ nanoparticles (a) $\mathrm{x}=0.02$ (b) $\mathrm{x}=0.06$ (c) $\mathrm{x}=0.08$

\section{Conclusion}

$\mathrm{Mn}_{1-\mathrm{x}} \mathrm{Co}_{\mathrm{x}} \mathrm{Fe}_{2} \mathrm{O}_{4}$ nanoparticles with an average size of $8 \mathrm{~nm}$ were synthesized by thermal decomposition method. $\mathrm{Mn}_{1-\mathrm{x}} \mathrm{Co}_{\mathrm{x}} \mathrm{Fe}_{2} \mathrm{O}_{4}(\mathrm{x}=0.02,0.06,0.08)$ nanoparticles were superparamagnetic at room temperature and ferromagnetic at the temperature of $5 \mathrm{~K}$. The blocking temperature and coercivity of nanoparticles increased monotonically with increasing Co addition. The saturated magnetization decreased slightly with increasing Co amount. $\mathrm{Mn}_{1-\mathrm{x}} \mathrm{Co}_{\mathrm{x}} \mathrm{Fe}_{2} \mathrm{O}_{4}$ nanoparticles have great applications in high-performance nanodevice, permanent magnets, and biomedicine.

\section{References}

[1] Sun S. H., Zeng H., Robinson D. B.,Raoux S., Rice P. M., Wang S. X., Li G. X..Monodisperse $\mathrm{MFe}_{2} \mathrm{O}_{4}(\mathrm{M}=\mathrm{Fe}, \mathrm{Co}, \mathrm{Mn})$ nanoparticles. Journalof American Chemical Society,2004,126 (1), 273-279.

[2] Park J., An K., Hwang Y., Park J. G., Noh H.J., Kim J. Y., Park J. H., Hwang N. M., Hyeon T.. Ultra-large scale syntheses of monodisperse nanocrystals. Nature materials, 2004, 3, 891-895

[3] Wu K. T. , Kuo P. C., Yao Y.D., Tsai E. H.. Magnetic and optical properties of $\mathrm{Fe}_{3} \mathrm{O}_{4}$ nanoparticle ferrofluids prepared by coprecipitation technique. IEEE Transactions on Magnetics[J], 2001, 37(4), 2651-2653

[4] Gas J, Poddar P, Almand J, Srinath S, Srikanth H . Superparamagnetic polymer nanocomposites with uniform $\mathrm{Fe}_{3} \mathrm{O}_{4}$ nanoparticle dispersions. Advanced Functional Materials[J],2006, 16(1),71-75

[5] Volkov I., Gudoshnikov S., Usov N., Volkov A., Moskvina M., Maresov A., Snigirev O., Tanaka S.. SQUID-measurements of relaxation time of $\mathrm{Fe}_{3} \mathrm{O}_{4}$ superparamagnetic nanoparticle ensembles. Journal of Magnetism and Magnetic Materials[J],2006, 300 (1), E294-E297

[6] Wu L. H., Jubert P. O., Berman D., Imaino W., Nelson A., Zhu H. Y., Zhang S., Sun S. H.. Monolayer Assembly of Ferrimagnetic $\mathrm{Co}_{\mathrm{x}} \mathrm{Fe}_{3-\mathrm{x}} \mathrm{O}_{4}$ Nanocubes for Magnetic Recording. Nano Letters[J],2004 
[7] Yu Y. S., Mendoza-Garcia A., Ning B., Sun S. H.. Cobalt-Substituted Magnetite Nanoparticles and Their Assembly into Freeimagnetic Nanoparticle Arrays. Advanced Material[J],2013,1-5

[8] Zeng H., Rice P. M., Wang S. X., Sun S. H.. Shaped-Controlled Synthesis and Shaped-Induced Texture of $\mathrm{MnFe}_{2} \mathrm{O}_{4}$ Nanoparticles. Journal of American Chemistry Society[J],2004,126, 11458-11459

[9] Song Q., Zhang Z. J.. Controlled Synthesis and Magnetic Properties of Bimagnetic Spinel Ferrite $\mathrm{CoFe}_{2} \mathrm{O}_{4}$ and $\mathrm{MnFe}_{2} \mathrm{O}_{4}$ Nanocrystals with Core-Shell Architecture. Journal of American Chemistry Society[J], 2014,134, 10182-10190

[10]Lima E., Winkler J. E. L., Tobia D., Troiani H. E., Sysler R. D., Agostinelli E., Fiorani D.. Bimagnetic CoO Core/CoFe ${ }_{2} \mathrm{O}_{4}$ Shell Nanoparticles: Synthesis and Magnetic Properties. Chemistry of Material[J],2014,24, 512-516

[11]Lee J. H., Jang J. T., Choi J. S.l, Moon S. H., Noh S. H., Kim J. W., Kim J. G., Kim I. S., Park K. I., Cheon J. W.. Exchange-coupled magnetic nanoparticles for efficient heat induction. Nature Nanotechnology[J],2011,16, 418-422 